\title{
Agromorphological Characterization of the Perfume Rose (Rosa damascena Mill.) of Kelâa M'Gouna-Dades, Morocco
}

\author{
Amal Aithida ${ }^{1,2 *}$, Abdelghani Tahiri ${ }^{3}$, Youssef Oubassine ${ }^{4}$, Khalil Cherif ${ }^{1}$, Mimoun Mokh- \\ tari $^{2}$, and Lalla Amina Idrissi Hassani ${ }^{1}$ \\ ${ }^{1}$ Faculty of Science, Ibn Zohr University, Agadir, Morocco; ${ }^{2}$ Horticulture \& Paysage, IAV Hassan II-CHA, \\ Campus d'Agadir, Agadir, Morocco $;{ }^{3}$ National Institute of Agricultural Research (INRA) - CRRA d'Agadir, \\ Agadir, Morocco; ${ }^{4}$ Faculty of Letters and Human Sciences, Ibn Zohr University, Agadir, Morocco.
}

Received: April 22, 2019 / Accepted: June 16, 2019

\begin{abstract}
Rosa damascena perfume rose has a considerable place in Morocco. The essential oil, hydrolate (rose water) and dried buds produced in Kalâa M'gouna are intended for export. However, local varieties are not identified. Hence, the objective of our research into the identification of morphological variability by studying 15 qualitative and quantitative characters related to leaf, prickle and flower, at eight localities along the valley of roses. The present study has demonstrated the existence of a great morphological variability within the Kalâa M'gouna's perfume rose. The characters associated with leaves and spines (prickles) drive this variability. The PCA analysis identified four morphotypes; the morphotype I whose stems are unarmed, the morphotype II characterized by broad leaves and moderately prickly stems, the morphotype III having stems bearing long prickle and whose petals are wider. Finally, the morphotype IV characterized by very prickly stems, leaves of reduced size and whose petals are wider.
\end{abstract}

* Corresponding author: a.aithida@gmail.com

\section{Introduction}

The genus Rosa comprise more than 200 species and 180000 cultivars that cover the entire northern hemisphere (Gudin 2000). The Rosaceae family includes more than 45 species including seven wild species that are the origin of the marketing of modern roses, widely used as ornamental plants and for the quality and virtues of their extracts and fruits. This makes the Rosa genus to have a broad economic and cultural influence (Matsumoto et al., 1998, Werlemark 2000a, Ritz et al., 2004).

The Canineae subgenera is characterized by a particulate meiosis linked to univalent ovum chromosomes (Blackburn 1925). This fecundation produces an asymmetry in heritability, which gives the offspring a strongly maternal character (De Cock et al., 2008). In this sense, taxon studies have revealed that the differences are less pronounced between taxa belonging to the same locality than between geographically spaced taxa (De Cock et al., 2008). Inter-fecundity between individuals, as well as the presence of both sexual and asexual reproductive modes, make taxa express a large polymorphism reflected sometimes by the presence of interspecific hybrids that are difficult to detect in a population (Werlemark et al. 2000b).

This variability has prompted researchers to move towards characterization via biotechnological tools, especially molecular markers (Antonelli et al., 1997; Babaei et al., 2007, Akond et al., 2012). However, the model developed by Christ in 1873, which is currently used for morphological characters, makes it possible to study the variability observed between individuals and taxa in a common space or between spaces whose barriers are more or less unnoticed (Casey et al., 2007; De Cock et al., 
2008). Maran et al. (2016) have demonstrated, in a study that focused on wild roses of high altitude in France, the existence of an important interspecific and intraspecific polymorphisms often linked to interactions and genetic mixing between individuals and / or more or less close species.

A multitude of hybrids from complex crosses between ancestral species from Eastern Europe and Asia are cultivated. Among these species, Rosa damascena (Mill.) is a tetraploid hybrid ( $8 \mathrm{n}=56$ chromosomes) (Saffari et al., 2011). Rosa damascena was considered a native of Middle East "Syria" (Chevalier 1996). In 2000, Iwata et al. demonstrated the triparental origin of this specie. While, Babaei et al (2007) conclude that Iran can be the center of biodiversity of this species. In Morocco; Rosa damascena is cultivated in the valley of M'gounDades, in the region of Ouarzazate hence its name the rose of M'gouna. The rose cultivation extends over 2400 linear $\mathrm{km}$ in the form of hedges and fences along the cultivated lands of the Dades Valley. (Anonymous 2005, Zrira 2006). This area is the equivalent of $10,000 \mathrm{ha}$, or $10 \%$ of the cultivated area in the region (Anonymous, 2005).

According to historical data, the Damascus rose was introduced in Morocco by the pilgrims of the South-East in Xth century (Zrira 2006, Oubaassine 2014). This species is integrated in the pillar II of the green Morocco plan. Despite the important place occupied by the perfume rose in Morocco particularly in the region of Ouarzazate, no study was interested in the study of the variability of Rosa damascena (Mill.).

The present work is interested to study the variability of Rosa damascena in the valley of M'gouna-Dades. At first to highlight the possible morphological variability within this population in Morocco, and in a second to select high-performance cultivars that meet the requirements of both producers (farmers) and consumers who would be interested in less or less thorny varieties, with a good yield of flower buds and essential oil. As well as by varieties easy to reproduce by cuttings.

\section{Material and Methods}

\section{Plant Material and Collection Site}

The study was conducted in Kelâa M'gouna region, Tinghir province (Figure 1). Kelâa M'gouna relief is represented by two mountains ranges: Saghro Mountain and the High Atlas Southern and Eastern flanks. The province is located in the latitudes North of $31^{\circ} 13^{\prime} 22^{\prime \prime}$ and Western longitude line of $6^{\circ} 13$ '21" (Oubaassine, 2014). This region belongs to the arid bioclimatic stage with a continental tendency. Rainfall is erratic and decreasing from north to south, with an annual average of $148 \mathrm{~mm}$, and mean temperatures ranging from $-5^{\circ} \mathrm{C}$ to $20^{\circ} \mathrm{C}$ in winter and $30^{\circ} \mathrm{C}$ to $40^{\circ} \mathrm{C}$ in summer (Taïbi and El Hannani, 2004).

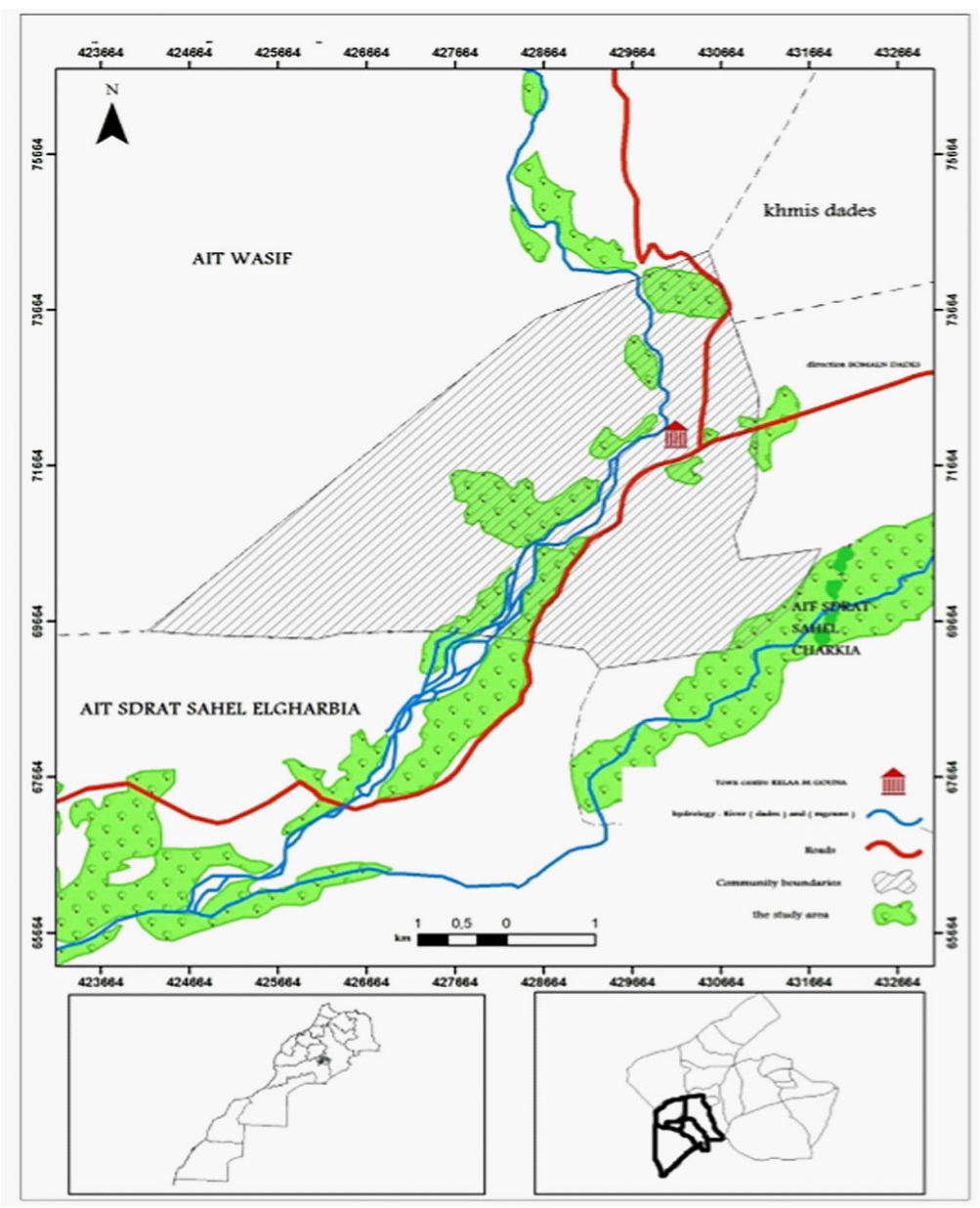

Figure 1. Topography map of Kelâa M'Gouna with location of the study area. 
Table 1. Geographical and soil characteristic of the 8 studied localities.

\begin{tabular}{|c|c|c|c|c|c|c|c|c|c|c|}
\hline Localities & $\begin{array}{c}\text { Altitude } \\
(\mathbf{m})\end{array}$ & Latitude & $\mathrm{pH}$ & $\begin{array}{c}\mathrm{EC}^{\circ} 5^{\circ} \mathrm{C}^{*} 10 \\
(\mathrm{~ms} / \mathrm{cm}) \\
\end{array}$ & $\begin{array}{c}\text { \% Organic } \\
\text { Matter }\end{array}$ & $\mathrm{CaCO}_{3}$ & $\begin{array}{c}\mathrm{Na}^{+} \\
(\mathrm{ppm})\end{array}$ & $\begin{array}{c}\mathbf{K}^{+} \\
(\mathrm{ppm})\end{array}$ & $\begin{array}{l}\mathrm{Ca} 2+ \\
(\mathrm{ppm})\end{array}$ & $\begin{array}{l}\mathrm{P}_{2} \mathrm{O}_{5} \\
(\mathrm{ppm})\end{array}$ \\
\hline L1 & 1400 & $\begin{array}{l}\mathrm{N} 31^{\circ} 13^{\prime} 54.1^{\prime \prime} \\
\mathrm{W} 6^{\circ} 6^{\prime} 30.7^{\prime \prime}\end{array}$ & 8.17 & 2.93 & 2.78 & 5.9 & 9.1 & 12.1 & 452.5 & 13.23 \\
\hline $\mathbf{L 2}$ & 1450 & $\begin{array}{l}\mathrm{N} 31^{\circ} 15^{\prime} 3.4^{\prime \prime} \\
\mathrm{W} 6^{\circ} 7^{\prime} 50.9^{\prime \prime}\end{array}$ & 8.27 & 3.17 & 2.47 & 6.3 & 11.6 & 9.1 & 502.5 & 21.15 \\
\hline L3 & 1500 & $\begin{array}{l}\mathrm{N} 31^{\circ} 15^{\prime} 37.5^{\prime \prime} \\
\mathrm{W} 6^{\circ} 6^{\prime} 25.00^{\prime \prime}\end{array}$ & 8.58 & 2.97 & 1.39 & 7.3 & 4.1 & 27.1 & 475 & 11.70 \\
\hline L4 & 1450 & $\begin{array}{l}\mathrm{N} 31^{\circ} 14^{\prime} 24.1^{\prime \prime} \\
\mathrm{W} 6^{\circ} 7^{\prime} 36.00^{\prime}\end{array}$ & 8.18 & 5.54 & 1.70 & 5.9 & 28.3 & 29.4 & 410 & 20.61 \\
\hline $\mathbf{L 5}$ & 1600 & $\begin{array}{l}\mathrm{N} 31^{\circ} 23^{\prime} 24.9^{\prime \prime} \\
\mathrm{W} 6^{\circ} 7^{\prime} 47.9^{\prime \prime}\end{array}$ & 7.95 & 3.39 & 4.18 & 5.9 & 10.4 & 20.1 & 545 & 10.35 \\
\hline L6 & 1600 & $\begin{array}{c}\mathrm{N} 31^{\circ} 17^{\prime} 59.5^{\prime \prime} \\
\mathrm{W} 6^{\circ} 2^{\prime} 16.0^{\prime \prime}\end{array}$ & 8.21 & 3.16 & 2.47 & 3.4 & 9.1 & 5.6 & 407.5 & 15.75 \\
\hline L7 & 1550 & $\begin{array}{l}\mathrm{N} 31^{\circ} 20^{\prime} 26.4^{\prime \prime} \\
\mathrm{W} 6^{\circ} 10^{\prime} 24.8^{\prime \prime}\end{array}$ & 8.09 & 3.76 & 2.43 & 3.3 & 9.4 & 7.0 & 242.5 & 10.35 \\
\hline L8 & 1400 & $\begin{array}{l}\mathrm{N} 31^{\circ} 11^{\prime} 42.6^{\prime \prime} \\
\mathrm{W} 6^{\circ} 12^{\prime} 51.1^{\prime \prime}\end{array}$ & 8.02 & 6.66 & 1.70 & 6.1 & 11.0 & 12.3 & 525 & 18.00 \\
\hline
\end{tabular}

\section{Study Site and Experimental Device}

Eight localities were chosen to carry out this study, to have a representativeness throughout the Rose Valley and to have sampling zones near the two main irrigation sources: wadi Dades and wadi M'goun (Figure 1).

The plots were chosen after a prospective study. The plantations, which are between five and ten years old and are maintained and pruned regularly, are involved in the study. At the level of each locality, three plots were randomly selected whose coordinates and altitude were determined by GPS the general characteristics of each locality are presented in Table 1.

\section{Experimental Methods}

The experimental device used is a random hierarchical block with five repetitions. At the level of each locality, three plots were chosen and at each plot, two hedges (rows) were chosen randomly. On each row, three plants at least three meters apart were designated for sampling, coded and labeled. At the level of each plant, five stems and five flower buds were collected and measured according to the characters studied.

\section{Agro-morphological Data Collection and Experimental Variables}

Biometric data measurement primarily focused on qualitative and quantitative characteristics related to the leaf, the prickle and the petal. In total, we studied seven qualitative variables and eight quantitative variables (Table 2).

The prospective study was performed during December 2014 where participants were rose producers. In this study, locations and labeling of selected plants was performed to able to trace them in further analysis.

Morphometric study was performed during the vegetative growth period (breaking dormancy to flowering) of M'gounaDades roses between February and May 2015.

For this, five stems were collected from each plant cut and placed in zipped plastic bags, labeled and afterwards, stored under cool conditions. In the laboratory, all stems were placed in water container to rehydrate prior to any observation and/or measurements. The upper leaflets were collected for measurements related to rose's leaves.

Prickles number (PN) was determined by counting pickle at $5 \mathrm{~cm}$ from the middle part of the stem. All five flower buds were collected in each plant and maintained in cold until measurement in the laboratory. Leaflets color was quantified by measuring the average of lively green leaflets color occurrence per location. Petals and leaves color was determined at the moment of sample collection in the field and was double-checked in the laboratory afterwards.

\section{Statistical Analyses}

All statistical analyses were performed using SPSS software Version 20.0. One-way analysis of variance (ANOVA) and multivariate analysis (MANCOVA) were completed to determine trait variability between locations as well as within location. Tukey's test at the $5 \%$ significance level was used to determine the homogeneous groups for each variable. Principal Component Analysis (PCA) is a multivariate statistical technique for exploration and simplifying complex data sets. PCA was performed after correlation analysis between different quantitative traits.

\section{Results}

\section{Analysis of the Diversity of Qualitative Characteristics}

\subsection{Leaflets}

At the level of all the plots studied, we found that the leaflet takes four distinct forms (Figure 2):

- The elongated form (EF),

- The oval form (OF),

- The obovoide form (OBF),

- The oval acuminate form (OAF). 
Table 2. Different qualitative and quantitative characteristics studied and their abbreviations.

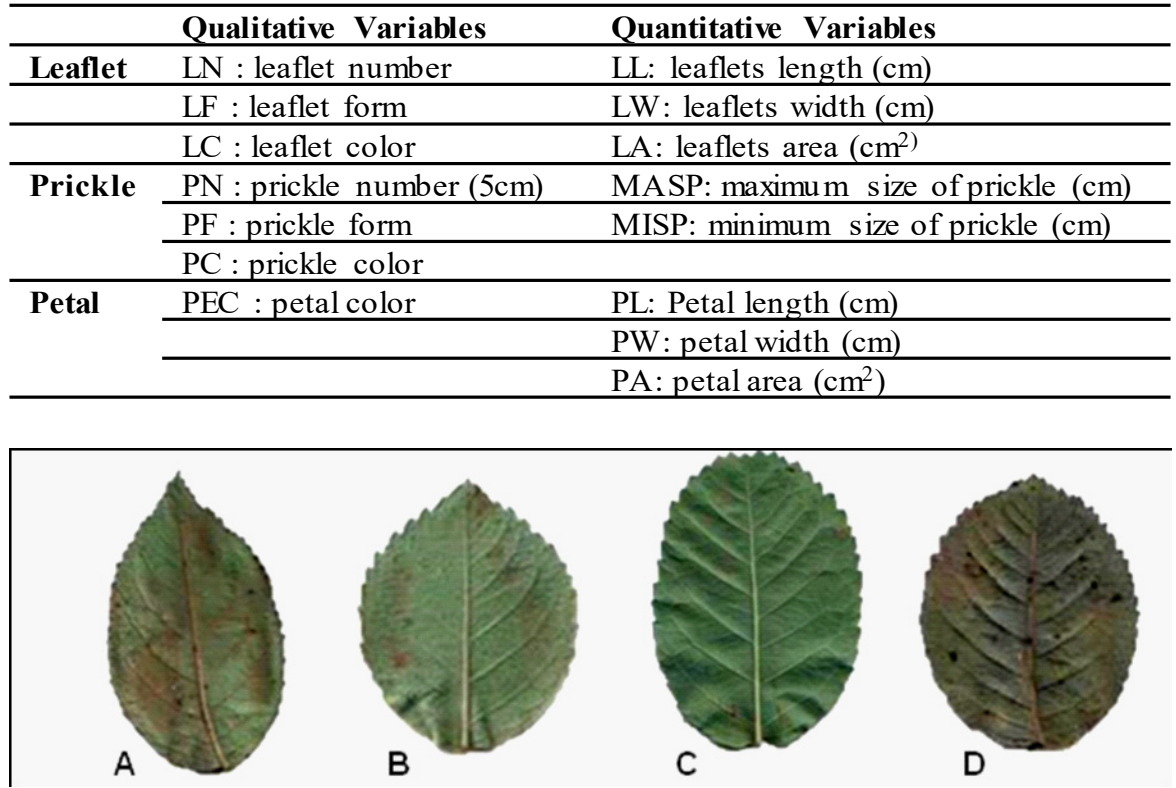

Figure 2. Different form of leaflet in the M'gouna-Dades rose. A: oval acuminate (OAF); B: obovoide (OBF); C: elongated (EF) and D: oval (OF).

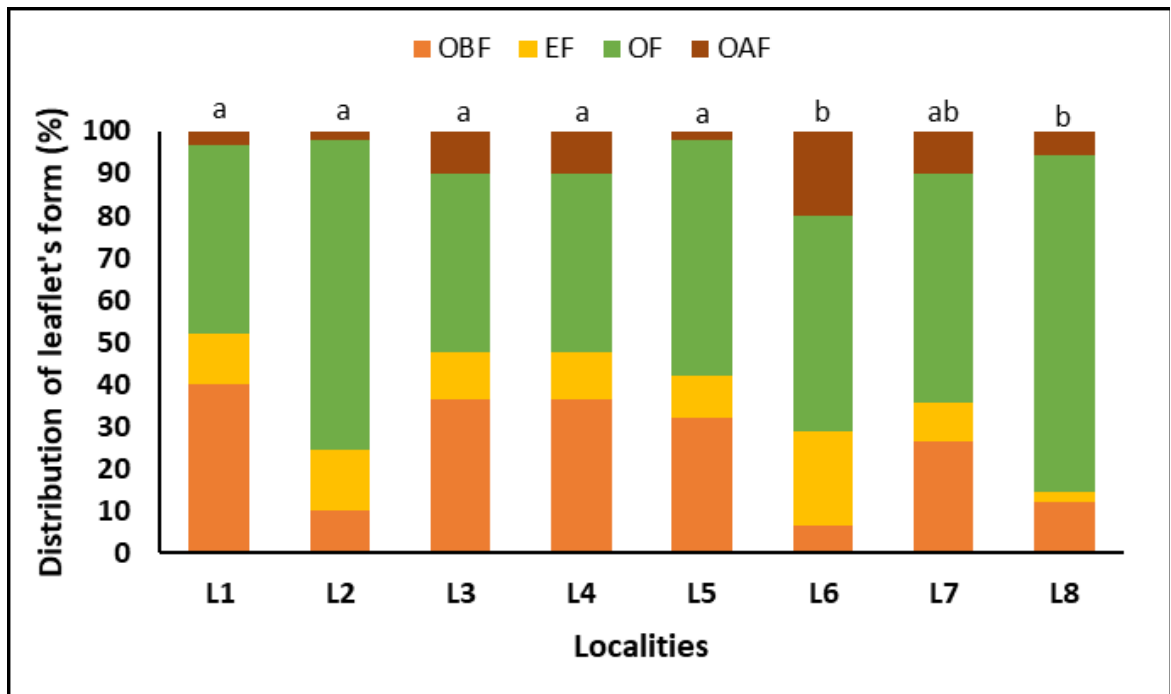

Figure 3. Distribution of different leaflet forms between localities. The same letters designate the homogeneous groups whose difference is not significant at the level $(p=0.05)$ by the Tukey test.

Four forms are found in all localities, with the predominant of oval form $(38-72 \%)$ that have the largest population in all localities (Figure 3).

The shape of the leaflets was quantified by assigning for each form a number from zero (for Obovoide form OBF) to 4 (for oval acuminate form $\mathrm{OAF}$ ) in every locality. The analysis of variance (ANOVA) revealed that there is a significant difference $(p=0.05)$ in the distribution of different forms between localities. Tukey test allowed us to identify three homogeneous groups with a major group comprising five localities L1, L2, L3, L4 and L5 (Figure 3).

Leaf cover varied from bright green $(\mathrm{BG})$ to pale green $(\mathrm{PG})$ depending on locality. A significant difference was observed in the distribution of leaflet color between localities (Figure 4). This variability is also observed between parcels within the same locality, except for locality L6 in which all of plants have bright green leaflets. Tukey's test revealed that for this character, localities are organized in six homogeneous groups. However, these groups remain very close together.

\subsection{Prickles}

For prickles, more or less homogeneous distribution of four different forms (needle shape NS, canine shape CAS, curved shape CS, hooked curved shape HCS) was observed with a dominance of needle and canine forms (Figure 5). As for the 


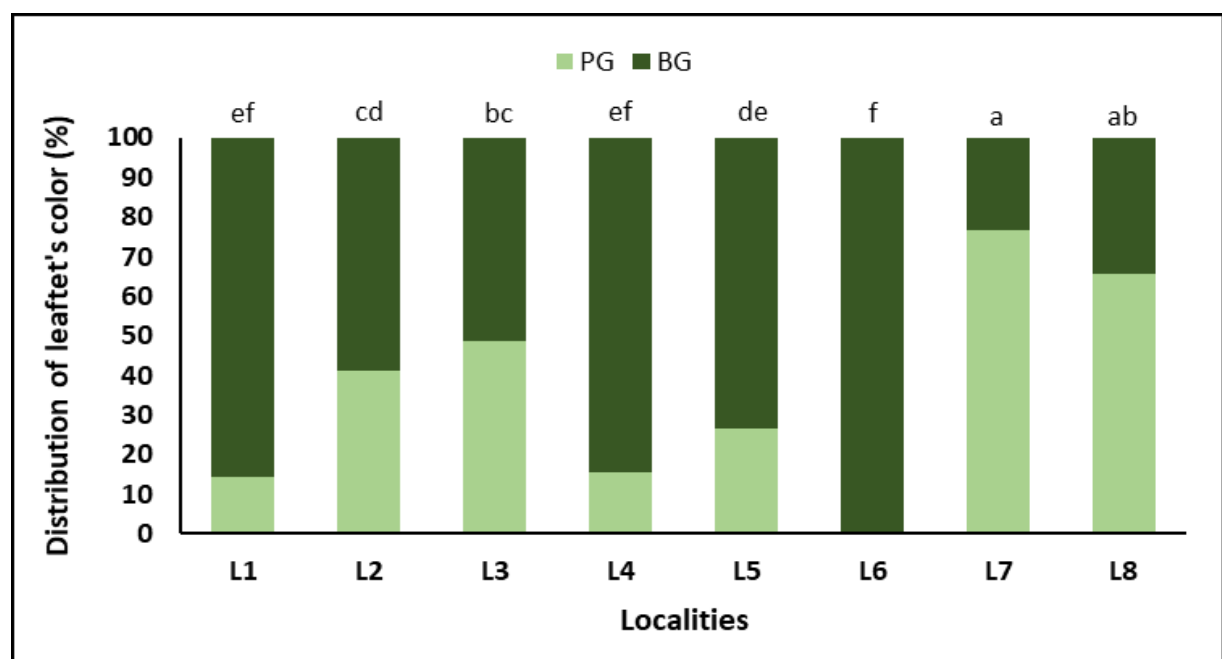

Figure 4. Distribution of leaflets color by locality. PG: Pale Green, BG Bright Green. The same letters designate the homogeneous groups whose difference is not significant at the level $(p=0.05)$ by the Tukey test.

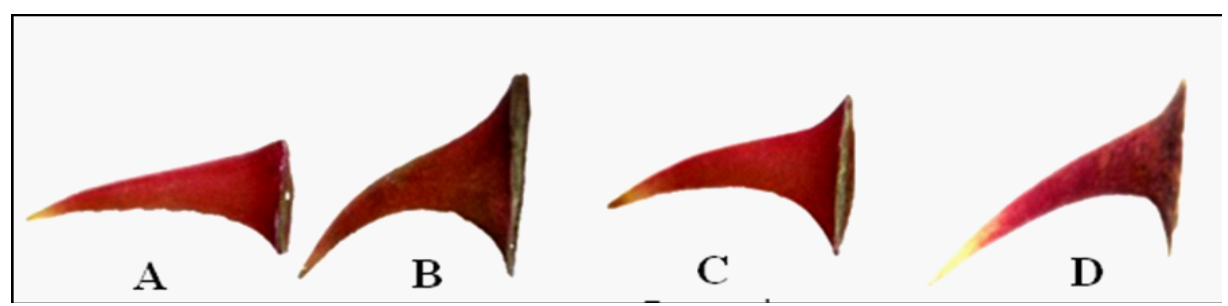

Figure 5. Different forms of prickle in the M'gouna-Dades rose. A: needle shape (NS); B: canine form (CAS); C: curved shape (CS) and D: curved shape hung (HCS).

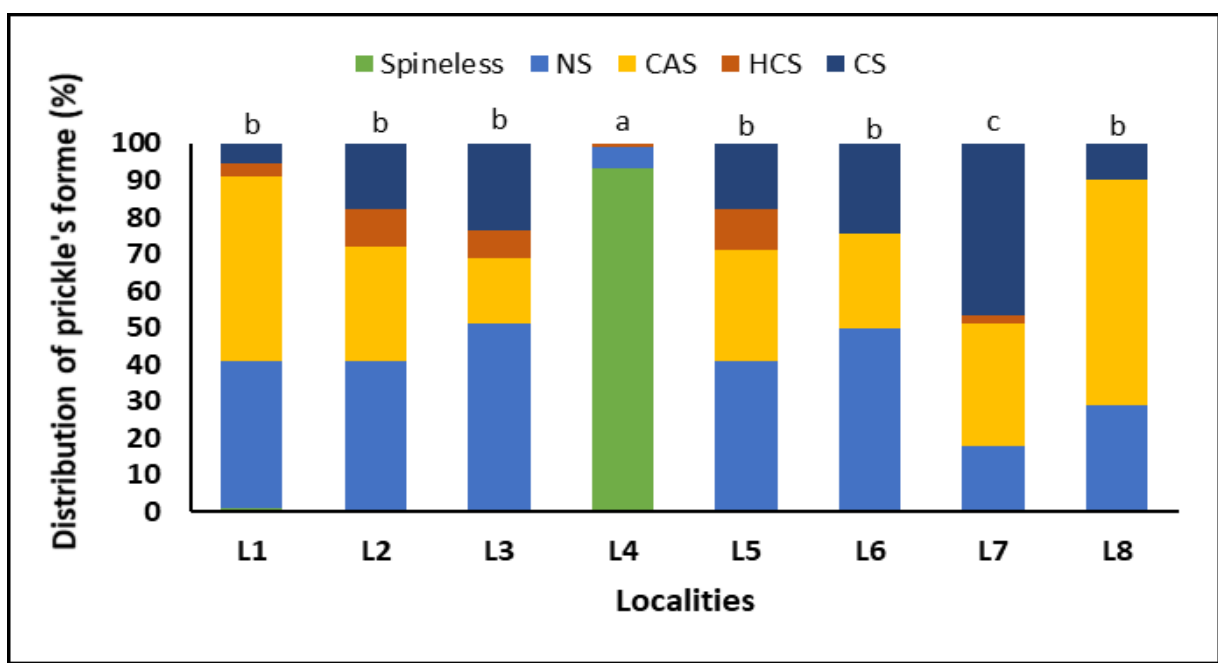

Figure 6. Distribution of different forms of prickles between localities. The same letters designate the homogeneous groups whose difference is not significant at the level $(p=0.05)$ by the Tukey test.

color of prickles, they are either brown or purple. Prickles with brown color (BC) are dominant compared to purple ones (PC).

Shape of pricklse was quantified by assigning a number from 0 (bare of prickles) to 4 (for the form HCS) for each form in every locality. Analysis of variance (ANOVA) revealed a significant difference for shape and color of prickles between localities. Tukey test allowed us to determine four homogeneous groups for these two parameters. Locality L4 represents a dis- tinct group since it includes plants without prickles on all plots. L1, L2, L3, L5, L6 and L8 localities are regrouped in second group characterized by the dominance of canine form. While, L7 locality is distinguished by the dominance of curved forms (CS and HCS (Figure 6).

Regarding the color of prickle, Tukey test revealed distribution to that obtained for prickle form. However, prickles with brown color remains ubiquitous (Figure 7). 


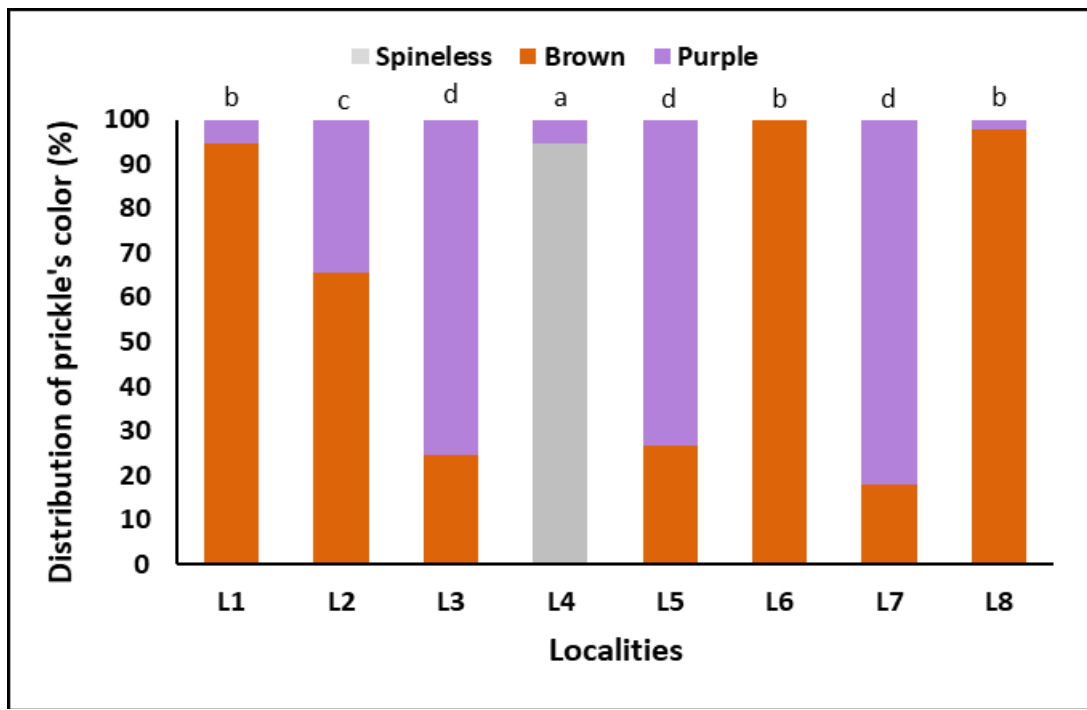

Figure 7. Distribution of the color of prickle according to the localities. The same letters designate the homogeneous groups whose difference is not significant at the level $(\mathrm{p}=0.05)$ by the Tukey test.

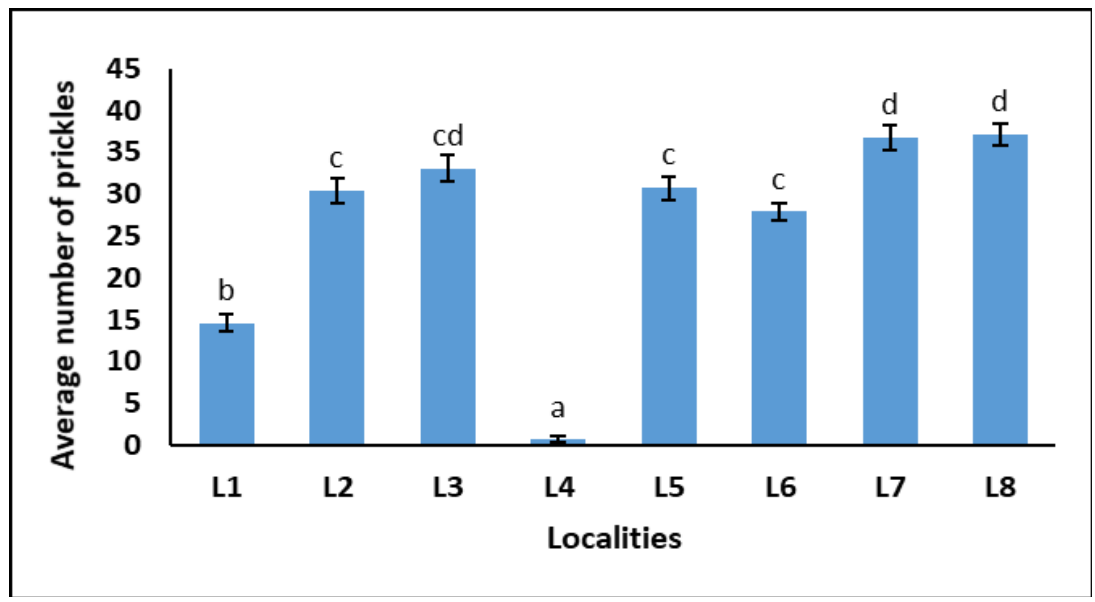

Figure 8. Average number of prickles by locality. The same letters designate the homogeneous groups whose difference is not significant at the level $(\mathrm{p}=0.05)$ by the Tukey test. (Counting is $5 \mathrm{~cm}$ from the middle part of the stem).

\section{Quantitative Characters Diversity}

Regarding the number of prickles, a variability between localities was noted. ANOVA analysis revealed a significant difference between the localities and the Tukey test determined four homogeneous groups. The major group brings together the localities L2, L3, L5 and L6 with a mean number of 30 prickles $/ 5 \mathrm{~cm}$ of stem. L4 locality represents a distinct group of plants without prickles. Plants of locality L1 are less prickly with an average number of 14.61 prickles $/ 5 \mathrm{~cm}$ of stem. While, L7 and L8 localities include plots with very prickly plants with an average number of 37 prickles $/ 5 \mathrm{~cm}$ of stem (Figure 8).

Prickles size varied generally within locality. Thus, in this study, we limited to the study of maximum size, which represents the maximum growth size. ANOVA analysis revealed a significant difference between the localities. Tukey test allowed us to determine four homogeneous groups. Major group contains plants of localities L1, L2, L3 and L6 with an average size of $0.5 \mathrm{~cm}$. However, L5 and L7 localities represent the group of plant characterized by prickles of medium size not exceeding $0.2 \mathrm{~cm}$. L8 plants have the longest prickles with an average length of $0.6 \mathrm{~cm}$. While, locality L4 remains distinct since almost all plants are without prickles (Figure 9).

It is interesting to note that variability of prickle size follows the same distribution as prickle number with high prickle density correlated with large spines prickle size. High values for both density and size are typically associated with needle type prickles.

\section{Correlations Between the Quantitative Characters Studied}

Significant positive correlations at 5\% level were noted between leaf-related traits with the largest value of Pearson coefficient noted between length and width of leaflet $(r=0.87)$ followed by correlation value between leaf area and leaf size ( $\mathrm{r}$ $=0.13$ ). Highly significant correlations at $1 \%$ level are obtained 


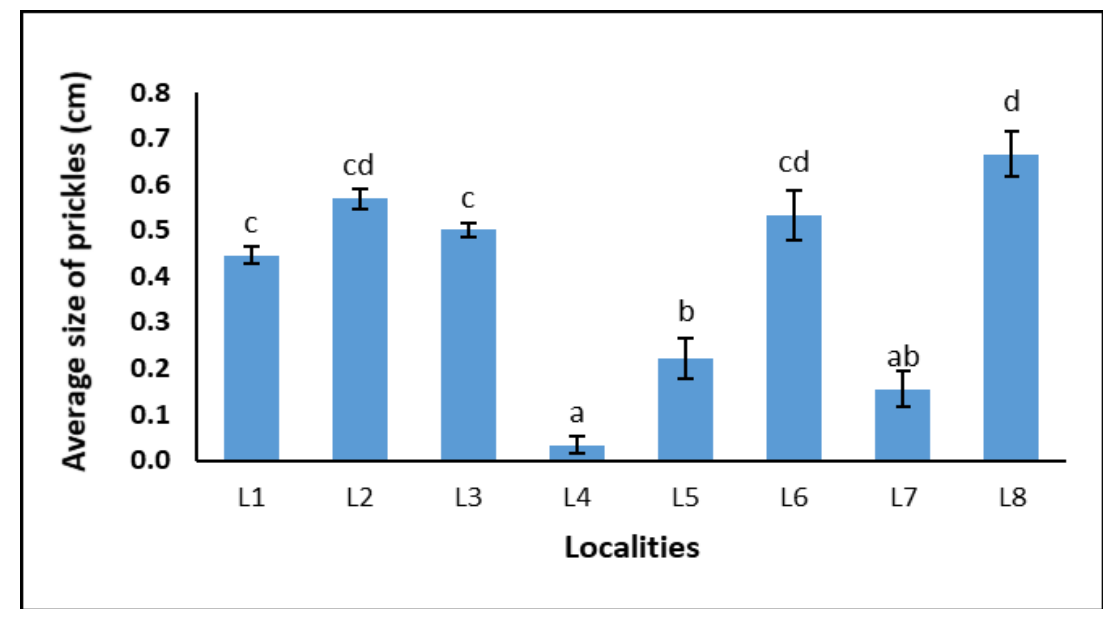

Figure 9. Average maximum size of prickles according to the localities. The same letters designate the homogeneous groups whose difference is not significant at the level $(\mathrm{p}=0.05)$ by the Tukey test.

Table 3. Correlations between the quantitative characters of the M'Gouna-Dades rose.

\begin{tabular}{lllllllll}
\hline & LL & LW & LA & PN & MASP & MISP & PL & PW \\
\hline LL & & & & & & & \\
\hline LW & $0.87^{*}$ & & & & & & & \\
\hline LA & $0.13^{*}$ & $0.13^{*}$ & & & & & & \\
\hline PN & 0.05 & $0.10^{* *}$ & -0.05 & & & & & \\
\hline MASP & $-0.25^{* *}$ & $-0.20^{* *}$ & 0.04 & $0.28^{* *}$ & & & & \\
\hline MISP & $-0.19^{* *}$ & $-0.12^{* *}$ & $0.24^{* *}$ & -0.04 & $0.14^{* *}$ & & & \\
\hline PL & -0.01 & -0.01 & $-0.16^{* *}$ & $0.13^{* *}$ & 0.04 & -0.04 & & \\
\hline PW & -0.07 & -0.07 & $-0.08^{*}$ & $0.04^{*}$ & 0.06 & -0.01 & 0.31 & \\
\hline PA & -0.07 & -0.07 & -0.10 & 0.06 & 0.07 & -0.02 & 0.43 & $0.99^{* *}$ \\
\hline
\end{tabular}

LL: Leaflet length, LW: leaflet width, LA: leaflet area, PN: prickle number (we consider $5 \mathrm{~cm}$ of the middle part of the stem), MASP: maximum size of prickles, MISP: minimum size of prickles, PL: Petal length, PW: petal width, PA: petal area*: significant correlation at the $5 \%$ level, $* *$ : significant correlation at the $1 \%$ level.

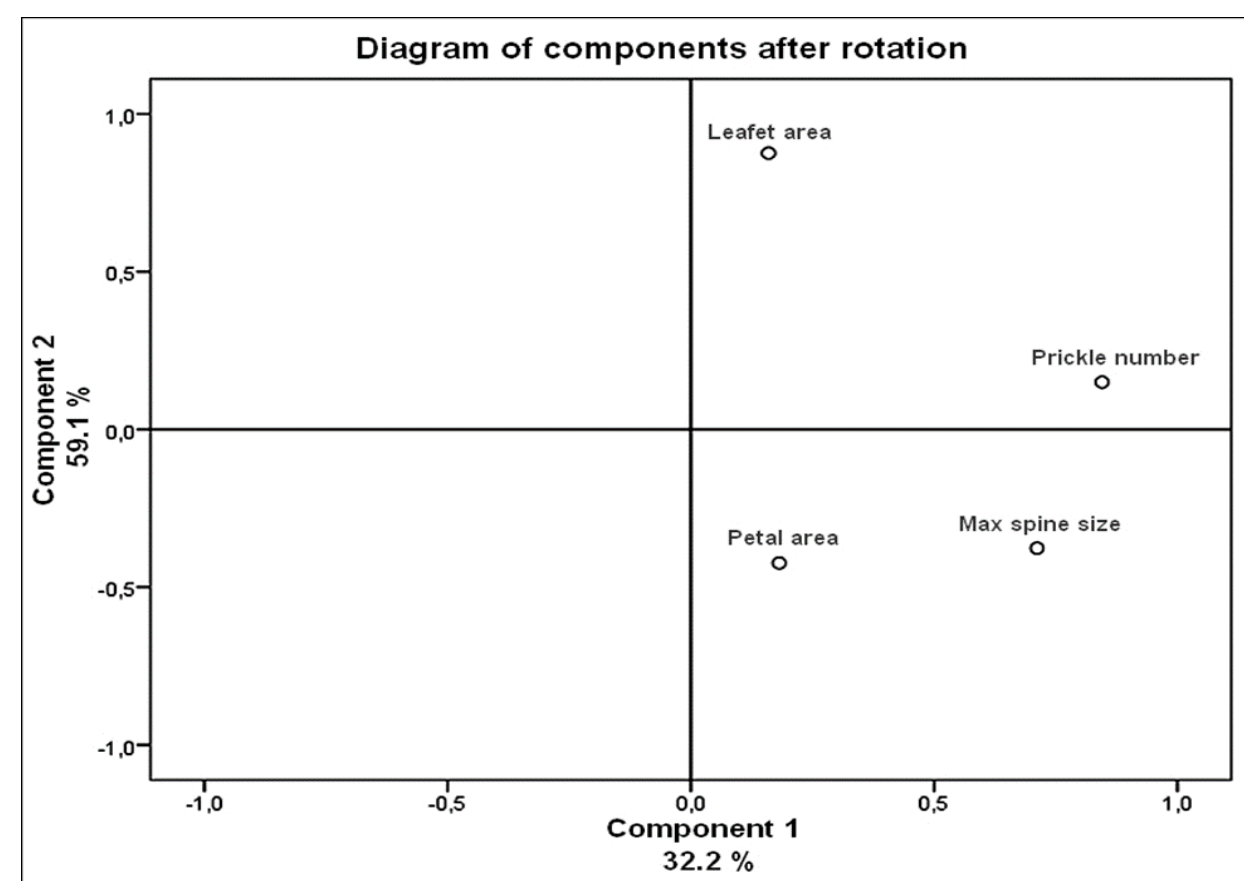

Figure 10. Diagram of components after rotation. 
between spiny and petal-related traits: low positive correlation between prickle number (PN) and petal length (PL) $(r=0.13)$. However, prickle related traits are negatively correlated with leaflet size, as well as between petal-related dimensions and leaf-related parameters (Table 2).

Correlation analysis between different quantitative traits revealed that traits related to the same organs are strongly correlated (e.g., for leaflet length and leaflet width $(r=0.87)$, leaflet area and leaflet width $(\mathrm{r}=0.13)$.

\section{Principal Component Analysis (PCA)}

For principal component analysis, four quantitative characteristics were chosen (leaflet area, petal area, prickle number, and maximum prickle size). These characters were considered in order to simplify the presentation by replacing characters that have a strong correlation by a single factor. (e.g., leaflet area instead of leaf length and leaf area).

Analysis revealed that variability observed in the M'gounaDades rose can be explained according to two components:

Table 4. Eigenvalue of principal components analysis for 4 studied characters.

\begin{tabular}{|c|c|c|c|c|c|c|c|c|c|}
\hline \multirow[t]{2}{*}{ Component } & \multicolumn{3}{|c|}{ Initial Eigenvalues } & \multicolumn{3}{|c|}{$\begin{array}{c}\text { Extraction Square Deviations of } \\
\text { the Selected Factors } \\
\end{array}$} & \multicolumn{3}{|c|}{$\begin{array}{c}\text { Square Deviations of the } \\
\text { Selected Factors to Rotation }\end{array}$} \\
\hline & Total & $\begin{array}{c}\% \text { of } \\
\text { variance }\end{array}$ & $\begin{array}{c}\text { Cumulative } \\
\% \\
\end{array}$ & Total & $\begin{array}{c}\% \text { of } \\
\text { Variance } \\
\end{array}$ & $\begin{array}{c}\text { Cumulative } \\
\% \\
\end{array}$ & Total & $\begin{array}{c}\% \text { of } \\
\text { Variance }\end{array}$ & $\begin{array}{c}\text { Cumulative } \\
\% \\
\end{array}$ \\
\hline 1 & 1,3 & 32,2 & 32,2 & 1,3 & 32,2 & 32,2 & 1,2 & 30,7 & 30,7 \\
\hline 2 & 1,1 & 26,9 & 59,1 & 1,1 & 26,9 & 59,1 & 1,1 & 28,4 & 59,1 \\
\hline 3 & 0,9 & 23,7 & 82,8 & & & & & & \\
\hline 4 & 0,7 & 17,2 & 100,0 & & & & & & \\
\hline
\end{tabular}

Table 5. Eigenvector of the two principal component axes for the 4 studied characters.

\begin{tabular}{lcc}
\hline & \multicolumn{2}{c}{ Component } \\
\cline { 2 - 3 } & $\mathbf{1}$ & $\mathbf{2}$ \\
\hline Prickle Number & 0,84 & 0,19 \\
\hline Leaflet Area & 0,06 & 0,83 \\
\hline Petal Area & 0,08 & $-0,53$ \\
\hline Max Prickle Size & 0,71 & $-0,37$ \\
\hline
\end{tabular}

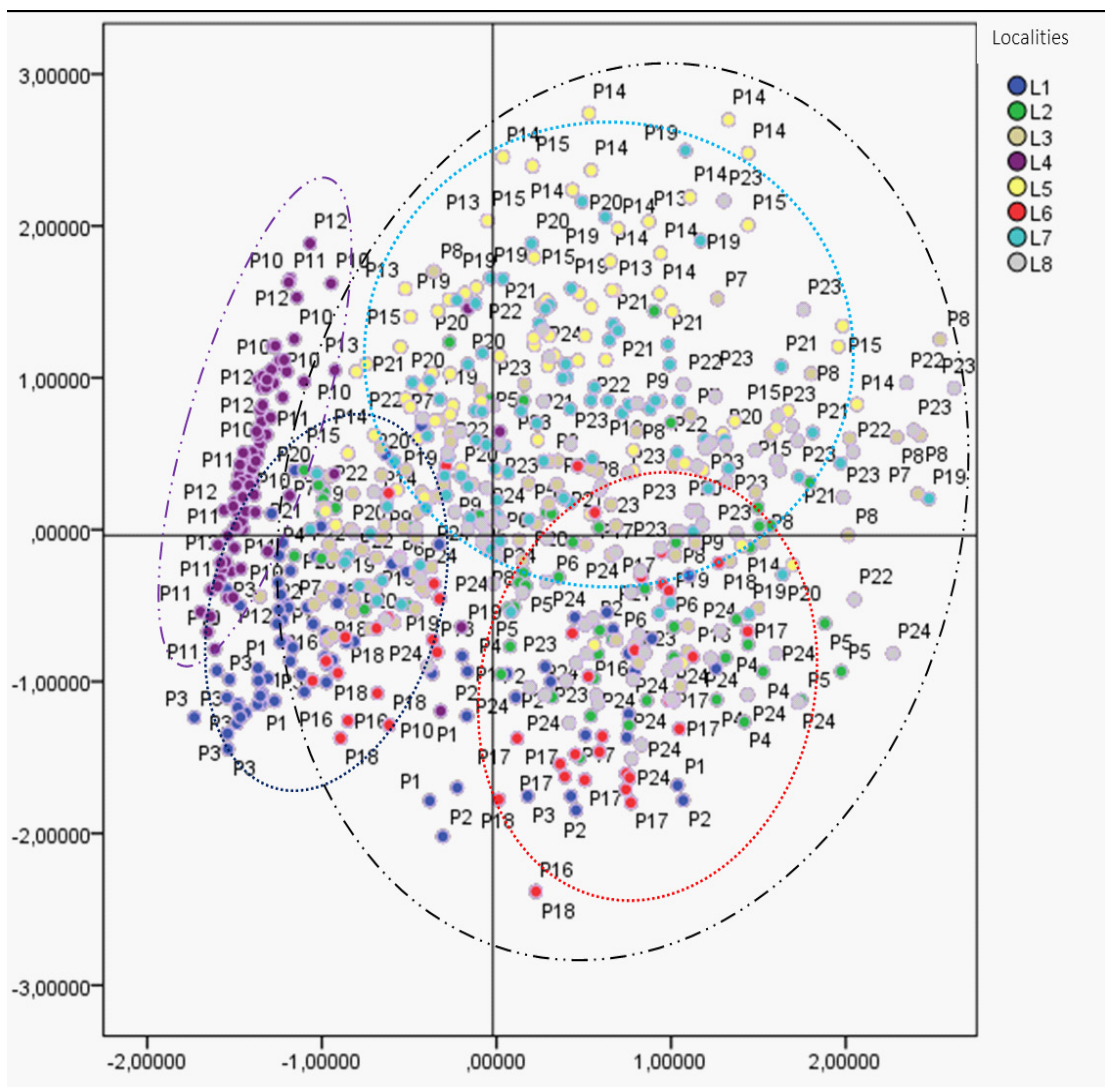

Figure 11. Representation of the set of individuals on the principal component diagram. 
Component 1 with a variance rate of $32.2 \%$ and component 2 with a variance explained at a rate of $26.9 \%$, giving a total of $59.1 \%$. Component 1 is mainly related to prickle related traits including prickle number with a value of 0.845 . While, component 2 is linked to the leaf with a value of 0.845 for leaflet area. However, surface of petals is negatively correlated with surface of leaflets, giving an explained variance of -0.424 according to component 2 (Figure 10 and Tables 4-5).

The principal component diagram revealed that two large groups could be distinguished. A first group (group I) containing plants of locality L4 and a second one (group II) grouping together other localities L1, L2, L3, L5, L6, L7 and L8. This second group is organized into three subgroups: subgroup I (formed by plants from L5, L7 and L8 localities), subgroup II (containing plants from L2 and L6 localities) and subgroup III (formed by plants of L1 and L3 localities) (Figure 11).

\section{Discussion}

\section{Agromorphological Variability}

This study revealed that rose of M'gouna-Dades (Rosa damascena Mill.) represent a morphological variability between all eight localities studied as well as within the same locality for qualitative and quantitative characteristics studied linked to leaves and prickles. These results are in accordance with those obtained for Turkish cultivars of Rosa damascena Mill (Baydar et al., 2004), and those obtained in Iran in a study of 41 genotypes collected from six provinces (Kiani et al., 2009). These studies have reported that Rosa damascena (Mill.) shows high morphological variability that is often related to genotypic variability.

Four forms of leaflets and prickles are found in eight localities. Although ANOVA analysis revealed a significant difference between localities and within the same locality for qualitative characteristics such as shape of leaflets and prickles. Frequency and abundance of one form relative to others determine the degree of variability that is demonstrated by this study. This variability could be due to genetic flow between zones of the region due to the traditional cultural mode replanting the root discharges that producers exchange between each other after maintenance and size of plantations in autumn. This polymorphism is less pronounced in large modern plantations, especially L1, L3 and L4, in which producers replant root discharges from their own plantations. Polymorphism was the subject of a study on wild rose in Tunisia. This study demonstrated that morphological variability of these roses is linked to genetic mixing and that allelic flow between generations resulted in a high morphological variability or creation of new hybrids (Cabes et al., 2015). This variability was also demonstrated by another study that focused on wild roses of high altitude in France (Maran et al., 2016). This study highlighted the existence of an important interspecific and intraspecific polymorphisms often linked to interactions and genetic mixing between individuals and / or more or less close species.

\section{Relations Betwen Characters}

This study revealed a significant correlation between characters related to leaf, and between parameters related to flower. There was also, a significant correlation between size and number of prickles. These results indicate that more the plant is prickly, the more it is robust, long and the flower is large. This relationship was the subject of a study in Iran that demonstrated a significant correlation between different parameters related to flower and prickle as well as between these traits and yield of essential oil (Tabaei-Aghdaei et al., 2007). Results of this study lead us to suppose that this morphological variability can be a source of variability in the composition of M'gouna-Dades rose extracts, notably essential oil and floral water (data not shown).

\section{Organization of Diversity}

Results of this study classified M'gouna-Dades rose into two large groups. Group I containing only plants of L4 locality distinguished by total absence of prickles and characterized by leaves of more or less significant size. While, second group is subdivided into three subgroups differentiated mainly by leaf size and prickle number.

The morphological characters may be applied as useful traits in evaluating rose germplasm collections and for selection and ranking of the clones (Babaei et al., 2008). The observed variability can be partially influenced by zone effect since in subgroups I and III we find plants belonging to neighboring localities M'goun's river (west side) and Dades river (East side) consecutively (Mirali et al., 2012). However, variability and heterogeneity observed within L8 locality revealed an important polymorphism of M'gouna-Dades rose, which can only be explained by genetic mixing that results from gene flow following the exchange of root rejects, allowing the appearance of new morphotypes. Four morphotypes can be distinguished in rose of M'gouna-Dades. The first morphotype (I) is characterized by a stem without prickles (prickleless) and a second one (morphotype II) characterized by wide leaves and moderately spiny stems. While, the third morphotype (III) is characterized by a stem with long prickles and wider petals. Finally, a very prickly stems, leaves of reduced size and wider petals characterize the last morphotype (IV).

\section{Conclusion}

The present study highlights the existence of great variability within perfume rose of M'gouna-Dades region of Morocco. Fifteen qualitative and quantitative characteristics were studied. The results obtained revealed that the observed variability in this species is associated with leaves and prickles characteristics. Four morphotypes having common characteristics and a more pronounced variability between localities than within the same locality was revealed. However, further experiments assisted by molecular markers will be needed to detect genetic variability of M'gouna-Dades rose population as well as to have more visibility compared to the origin of introduction of Rosa Damascena (Mill.) in southwestern Morocco. 


\section{Acknowledgements}

The authors would like to thank the cooperatives and producers who have agreed to participate in this study, and the Regional Center for Agricultural Development of Kelâa M'gouna. In addition, we thank Mr. Christian PAMIES founder of the HEVEA laboratory in Spain and owner of Naturlab for his technical assistance.

\section{References}

Akond M, S Jin and X Wang (2012) Molecular characterization of selected wild species and miniature roses based on SSR markers. Scientia Horticulturae 147: 89-97.

Andreo L, M Berenger, P Bernini, F Dory, M Hamon, N Le Galliot and M Perard (2017). Différenciation de taxons au sein du genre Rosa Section Caninae sur la base de caractères morphologiques. Mimoire de fin d'étude, université de Aix Marseille.

Anonymeous (2005) Ouarzazate: Potentialités humaines, economiques et touristiques, ORMVA, Ouarzazate.

Antonelli A, C Fabbri, ME Giorgioni and R Bazzocchi (1997) Characterization of 24 Old Garden Roses from Their Volatile Compositions. Journal of Agricultural and Food Chemistry 45: 4435- 4439.

Babaei A, SR Tabaei-Aghdaei, M Khosh-Khui, R Omidbaigi, MR Naghavi, GD Esselink and MJ Smulders (2007) Microsatellite analysis of Damask rose (Rosa damascena Mill.) accessions from various regions in Iran reveals multiple genotypes. BMC Plant Biology 7: 12 .

Babaei AR, AS Tabaei,, M Naghavi, M. Khoushkhoui and M Asareh (2008) Rosa damascena (Rosaceae) characters and their heritability analysis in Iran. Iranian Journal of botany 14 (1):75-80.

Basim E, and H Basim (2003) Antibacterial activity of Rosa damascena essential oil. Fitoterapia 74(4): 394-396.

Baydar N, H Baydar and T Debener (2004) Analysis of genetic relationships among Rosa damascena plants grown in Tyrkey by using AFLP microsatellite markers. Biotechnology Advances 111: 263267.

Blackburn KB (1925) Chromosomes and classification in the genus Rosa. The American Naturalist 59(662): 200-205.

Boskabady MH, MN Shafei, Z Saberi and S Amini (2011) Pharmacological effects of Rosa damascena. Iranian journal of basic medical sciences 14(4): 295.

Cabes D, A Courtial, C Danovaro, C Gutigny, L Miron, P Andréa and E Valadas (2015) Etude du polymorphisme du complexe Rosa. compte rendu MedNet : Réseau Méditerranéen d'Ecoles pratiques environnementales 1-9.

Casey C, J Newman, K Robb, S Tjosvold, J MacDonald and M Parrella (2007) IPM program successful in California greenhouse cut roses. California agriculture 61(2): 71-78.

De Cock K, K Vander Mijnsbrugge, P Breyne, E Van Bockstaele and J Van Slycken (2008) Morphological and AFLP-based differentiation within the taxonomical complex section Caninae (subgenus Rosa). Annals of botany 102(5): 685-697.

Gudin S (2000) Rose: genetics and breeding. Plant breeding reviews 17: $159-190$.

Guoliang W (2003) History of roses in cultivation| Ancient Chinese Roses. Encyclopedia of Rose Science 387-395.

Haghighi M, A Tehranifar, A Nikbakht and M Kafi (2006) Research and current profile of Iranian production of damask rose (Rosa damascena Mill.). XXVII International Horticultural CongressIHC2006: International Symposium on Asian Plants with Unique Horticultural 769.

Iwata H, T Kato and S Ohno (2000) Triparental origin of Damask roses. Gene 259(1): 53-59.

Kiani M, Z Zamani, A Khalighi, R Fatahi and D Byrne (2009) A unique germplasm of damask roses in Iran. V International Symposium on Rose Research and Cultivation 870.

Mahboubi M (2016) Rosa damascena as holy ancient herb with novel applications. Journal of Traditional and Complementary Medicine 6(1): 10-16.

Maran M, I Mook, S Pacquet, A Ramond, R Roques and Y Sanaa (2016) Rôle des effets de voisinage dans la structure du polymorphisme des rosiers. Mémoire de Master sciences de l'environnement terrestre Université de Aix Marseille.

Matsumoto S, M Kouchi, J Yabuki, M Kusunoki, Y Ueda and H Fukui (1998) Phylogenetic analyses of the genus Rosa using the matK sequence: molecular evidence for the narrow genetic background of modern roses. Scientia Horticulturae 77(1): 73-82.

Mirali N, R Aziz and I Nabulsi (2012) Genetic characterization of Rosa damascena species growing in different regions of Syria and its relationship to the quality of the essential oils. International Journal of Medicinal and Aromatic Plants 2(1): 41-52.

Oubaassine Y (2014) The evaluation of the resources of the land of Dades Al-Ward and the role of the actors in the construction of a strategic project for the development of the sector. Memoir de fin d'étude, université Ibn Zohr.

Ritz C, MH Schmuths and V Wissemann (2004) Evolution by Reticulation: European Dogroses Originated by Multiple Hybridization Across the Genus Rosa. Journal of Heredity 96(1): 4-14.

Saffari VR, GR Sharifi-Sirchi and MH Torabi-Sirchi (2011) Enhancing rooting consistency in Rosa damascena scions. African Journal of Biotechnology 10(73): 16495-16500.

Tabaei-Aghdaei SR, A Babaei, M Khosh-Khui, K Jaimand, MB Rezaee, MH Assareh and MR Naghavi (2007) Morphological and oil content variations amongst Damask rose (Rosa damascena Mill.) landraces from different regions of Iran. Scientia Horticulturae 113(1): 44-48.

Taïbi AN and M El Hannani (2004) Mutation des modes de gestion et "crise" de l'eau au Maghreb: d'une gestion collective à une gestion individuelle. Le cas du bassin du Dadès (Maroc). ESO Travaux et Documents (22): 61-66.

Werlemark G (2000a) Evidence of apomixis in hemisexual dogroses, Rosa section Caninae. Sexual Plant Reproduction 12(6): 353-359.

Werlemark G, H Nybom, A Olsson and M Uggia (2000b) Variation and inheritance in hemisexual dogroses, Rosa section Caninae. Biotechnology \& Biotechnological Equipment 14(2): 28-31.

Widrlechner MP (1981) History and utilization of Rosa damascena. Economic Botany 35(1): 42-58.

Yassa N, F Masoomi SR Rankouhi and A Hadjiakhoondi (2009) Chemical composition and antioxidant activity of the extract and essential oil of Rosa damascena from Iran population of Guilan. DARU Journal of Pharmaceutical Sciences 17(3): 175-180.

Zrira S (2006) La rose de Dadés: culture et technologies d'extraction des essences de rose. Bulletin mensuel d'information et de liaison du PNTTA 146 : 1-4.

Zrira S (2017) Some Important Aromatic and Medicinal Plants of Morocco. Medicinal and Aromatic Plants of the World-Africa 3:91125 . 